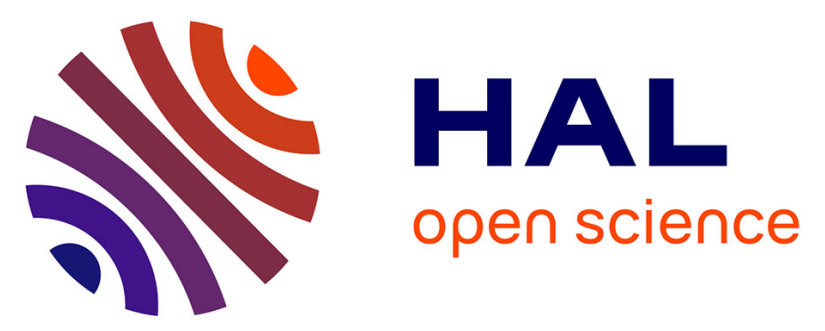

\title{
New bio-based thermoplastic polyurethane elastomers from isosorbide and rapeseed oil derivatives
}

Héloïse Blache, Françoise Mechin, Alain Rousseau, Etienne Fleury, Jean-Pierre Pascault, Pierre Alcouffe, Nicolas Jacquel, René Saint-Loup

\section{To cite this version:}

Héloïse Blache, Françoise Mechin, Alain Rousseau, Etienne Fleury, Jean-Pierre Pascault, et al.. New bio-based thermoplastic polyurethane elastomers from isosorbide and rapeseed oil derivatives. Industrial Crops and Products, 2018, 121, pp.303-312. 10.1016/j.indcrop.2018.05.004 hal-02010781

\section{HAL Id: hal-02010781 \\ https://hal.science/hal-02010781}

Submitted on 9 May 2019

HAL is a multi-disciplinary open access archive for the deposit and dissemination of scientific research documents, whether they are published or not. The documents may come from teaching and research institutions in France or abroad, or from public or private research centers.
L'archive ouverte pluridisciplinaire HAL, est destinée au dépôt et à la diffusion de documents scientifiques de niveau recherche, publiés ou non, émanant des établissements d'enseignement et de recherche français ou étrangers, des laboratoires publics ou privés. 


\title{
New bio-based thermoplastic polyurethane elastomers from isosorbide and rapeseed oil derivatives
}

Héloïse Blache ${ }^{\mathrm{a}}$, Françoise Méchin ${ }^{\mathrm{a}}$, Alain Rousseau, Étienne Fleury ${ }^{\mathrm{a}}$, Jean-Pierre Pascault ${ }^{\mathrm{a}}$, Pierre $^{\mathrm{a}}$ Alcouffe $^{a}$, Nicolas Jacquel ${ }^{b}$, René Saint-Loup ${ }^{b}$

a. Univ Lyon, INSA-Lyon, CNRS UMR 5223, Ingénierie des Matériaux Polymères, F- 69621, Villeurbanne Cedex, France

b. Roquette Frères, Polymer Chemistry Department, 62136 Lestrem, France

\begin{abstract}
Thermoplastic polyurethanes (TPUs) from fatty acids dimer-based polyester polyols, 4,4'-methylene bis(phenyl isocyanate) (MDI) and isosorbide (ISO) as chain extender were successfully synthesized by a two-stage synthesis. TPUs obtained from isosorbide were compared to the model 1,4-butanediol (BDO) -based materials. Differential scanning calorimetry revealed the phase-separated structure of these materials that displayed a typical thermoplastic elastomer behavior by dynamic mechanical analysis. Samples were further analyzed by transmission electronic microscopy, atomic force microscopy and compression set; hardness and water uptake were also monitored. Isosorbide was found to slightly increase the glass transition and melting temperatures of MDI-based hard segments, and to slightly decrease the stability and quality of phase segregation. This resulted in an increase in rubber modulus and hardness, shape retention, in a slight increase in the temperature of the $\alpha$ relaxation of the soft segment domains and in a characteristic microphase morphology. Moreover the use of the rather hydrophobic fatty acid-based soft segment allowed to keep the water uptake at a rather low level, in spite of the presence of isosorbide in the formulation.
\end{abstract}

Keywords : thermoplastic polyurethanes; bio-based building blocks; isosorbide; fatty acid dimer based polyester polyol; phase segregation; water uptake

Published in Industrial Crops \& Products, vol. 121, 303-312 (2018) 


\section{Introduction}

Sustainability has become a key factor in the development of technologies in the late 20th century. As such, finding alternatives to the use of petroleum-based chemicals in the elaboration of plastics is one of the main challenges of modern-day chemistry. Easily accessible replacements usually include molecules derived from vegetable oils and sugars. In this context, isosorbide (ISO) is a green monomer from the group of 1,4:3,6-dianhydrohexitol isomers. It is obtained from starch through a three-step synthesis route (Flèche and Huchette, 1986). In addition to its sustainable origin, isosorbide is also a non-toxic, aliphatic, chiral and rigid molecule. These structural properties have been known to induce a high glass transition temperature, and higher hardness in several types of polycondensates such as polycarbonates, polyamides or polyesters (Fenouillot et al., 2010). As such, its use as a chain extender for thermoplastic polyurethanes has a huge impact on the thermal and mechanical properties of such materials compared to more classical petroleum-sourced molecules, and increases the bio-sourced content of these polymers. The secondary nature of the hydroxyls and the $\mathrm{H}$-bond formed by the endo-hydroxyl with the adjacent oxygen atom (Figure 1) decreases a lot the reactivity of isosorbide compared to classical primary di-alcohols such as 1,4-butanediol. It has however been shown that when paired with a much more reactive aromatic isocyanate function such as those displayed by phenyl isocyanate, p-tolyl-isocyanate or $4,4^{\prime}$-diphenylmethylene diisocyanate (MDI), both hydroxyl functions of isosorbide can be considered quasi-equireactive (Cognet-Georjon et al., 1995, 1996; lonescu et al., 2011; Li et al., 2014).

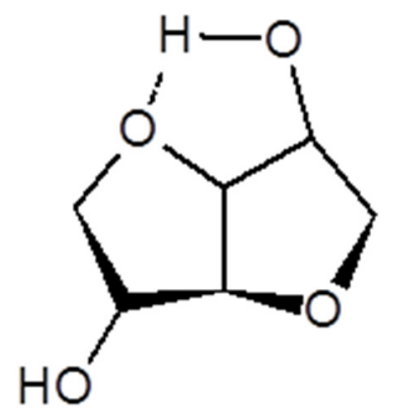

\section{Figure 1: Spatial structure of isosorbide}

The first use of isosorbide for the synthesis of polyurethanes was reported in the mid-80's (Dirlikov and Schneider, 1984; Thiem and Lueders, 1986), however the first report of a thermoplastic polyurethane containing isosorbide originates from Cognet-Georjon (Cognet-Georjon et al., 1996) and the interest in those materials has only been renewed around the year 2010 (Marin and MuñozGuerra, 2009; Tsui and Gogolewski, 2009; Park et al., 2013; Kim et al., 2014; Oh et al., 2015; Javni et al., 2015a; Lee et al., 2009). In order to obtain thermoplastic polyurethanes, it is required to synthesize linear multiblock copolymers composed of alternating hard and soft segments, the soft segments (SS) being composed of a flexible oligomer diol with a molar mass generally between 500 and 3,000 g. mol ${ }^{-1}$, while the hard segments (HS) are composed of an alternating pattern of diisocyanates and short diols. In this prospect, poly(tetrahydrofuran) (PTMEG) (Cognet-Georjon et al., 1996; Kim et al., 2014; Javni et al., 2015a) or polycaprolactone (PCL) diols (Marìn and Muñoz-Guerra, 2009; Tsui and Gogolewski, 2009; Park et al., 2013) were very often used as soft segments in combination with hard segments composed of isosorbide and either MDI (Cognet-Georjon et al., 1996; Marìn and Muñoz-Guerra, 2009; Javni et al., 2015b) or 1,6-hexamethylene diisocyanate (Marìn and Muñoz-Guerra, 2009; Tsui and Gogolewski, 2009; Park et al., 2013; Kim et al., 2014; Oh et al., 
2015), mainly for applications requiring biodegradation, biocompatibility or good mechanical properties. Isosorbide is intended to be used in such PU formulations as a new green building block and as an alternative for the very common and widely spread 1,4-butanediol (BDO), in order to bring new properties (Marìn and Muñoz-Guerra, 2009; Javni et al., 2015b; Marìn et al., 2012; Charlon et al., 2014). It appears that this replacement by ISO often induces smaller molar masses, but greatly increases the glass transition temperature of the hard segments (Lee et al., 2009; Oulame et al., 2015). It was moreover shown (Marin et al., 2012) that the use of ISO as a chain extender affects both crystallization degree and crystal form compared to BDO in PCL-based polyurethanes. It is expected as well that the phase segregation will be impacted as the combination of macrodiol, diisocyanate and chain extender strongly influences the microphase morphology (Yilgör et al., 2015). Finally recently, isosorbide was also successfully incorporated in novel polyhydroxyurethanes, PHUs, obtained by an isocyanate-free route (Besse et al., 2013). For this purpose the authors prepared isosorbide dicyclocarbonates and these new precursors were then reacted with various diamines. Once again the presence of isosorbide induced interestingly high Tgs by comparison with what is usually observed for PHUs, and this method could represent a promising alternative to more traditional processes once the issues related to low molar masses can be worked out.

Increasing the bio sourced content can also be achieved by using bio-sourced soft segments and diisocyanate, particularly vegetable oil-derived building blocks. Thus, fatty acid dimer-derived polyester soft segments used to synthesize TPUs were reported (Bueno-Ferrer et al., 2012a, 2012b; Carré et al., 2014, 2015, 2016). However, most materials obtained were amorphous except when associated with $\mathrm{MDI}$ and BDO, resulting in poor mechanical properties. Some authors (Charlon et al., 2014) were able to synthesize an entirely bio-based PU containing isosorbide and a partially bio-sourced di-isocyanate obtained from fatty acid dimers, called 2-heptyl-3,4-bis(9-isocyanatononyl)-1-pentylcyclohexane (DDI). However, the mechanical properties of the obtained material were rather poor due to the lack of rigid and crystallization prone di-isocyanate. Other authors (Calvos-Correas et al., 2016) also used DDI in formulations with castor oil and isosorbide and obtained materials displaying phase segregation and a melting temperature around $60^{\circ} \mathrm{C}$.

In this study, we report the synthesis of several new TPUs based on ISO/MDI hard segments associated with a rapeseed oil-issued polyester polyol, with a number average molar mass 2,200 g.mol ${ }^{-1}$. In order to obtain insight into the effects of the hard segment content and the phase segregation quality, stoichiometry between SS and HS was varied. Model TPUs containing BDO as a chain extender were as well synthesized following the same method in order to compare the properties brought by ISO.

\section{Materials and methods}

\subsection{Materials}

The bio-based polyester macrodiol, Radia 7282 (FADM) used in this study was a gift from Mérylithe (France). It is produced by Oleon and made of dimeric fatty acids from hydrogenated rapeseed oil, adipic acid and hexanediol with renewable content $43 \%$ and number average molar mass $\left(M_{n}\right)$ around 2,200 g.mol ${ }^{-1}$ according to the supplier. Hydroxyl and acid values as measured by the supplier were 55 and $0.5 \mathrm{mg} .\left(\mathrm{g}_{\mathrm{KO}}\right)^{-1}$, respectively. The ${ }^{1} \mathrm{H}$ NMR characterization of the hydrogenated rapeseed oil-derived polyester polyol (FADM) can be found in the Supplementary Content, and one of the main possible chemical structures is shown in Scheme 1. 
4,4'-diphenylmethylene diisocyanate (MDI) and dibutyltin dilaurate (DBTDL) were purchased from Sigma-Aldrich and used as received. Isosorbide (ISO), sold under the trade name Polysorb $P$, was kindly supplied by Roquette (France) and dried under nitrogen flux at $100^{\circ} \mathrm{C}$. 1,4-butanediol (BDO) was purchased from Sigma-Aldrich and dried under nitrogen flux at $100^{\circ} \mathrm{C}$. The hydroxyl number of both chain extenders were determined by chemical titration and found in perfect agreement with the theoretical values.

\subsection{Synthesis of polyurethanes}

Eight different TPUs were prepared in bulk with a slight excess of $\mathrm{NCO}(\mathrm{NCO} / \mathrm{OH}$ ratio $=1.02)$ and $\mathrm{HS}$ content ranging from $25 \mathrm{wt} \%$ to $50 \mathrm{wt} \%$, by a two-stage synthesis process as shown in Scheme 1.
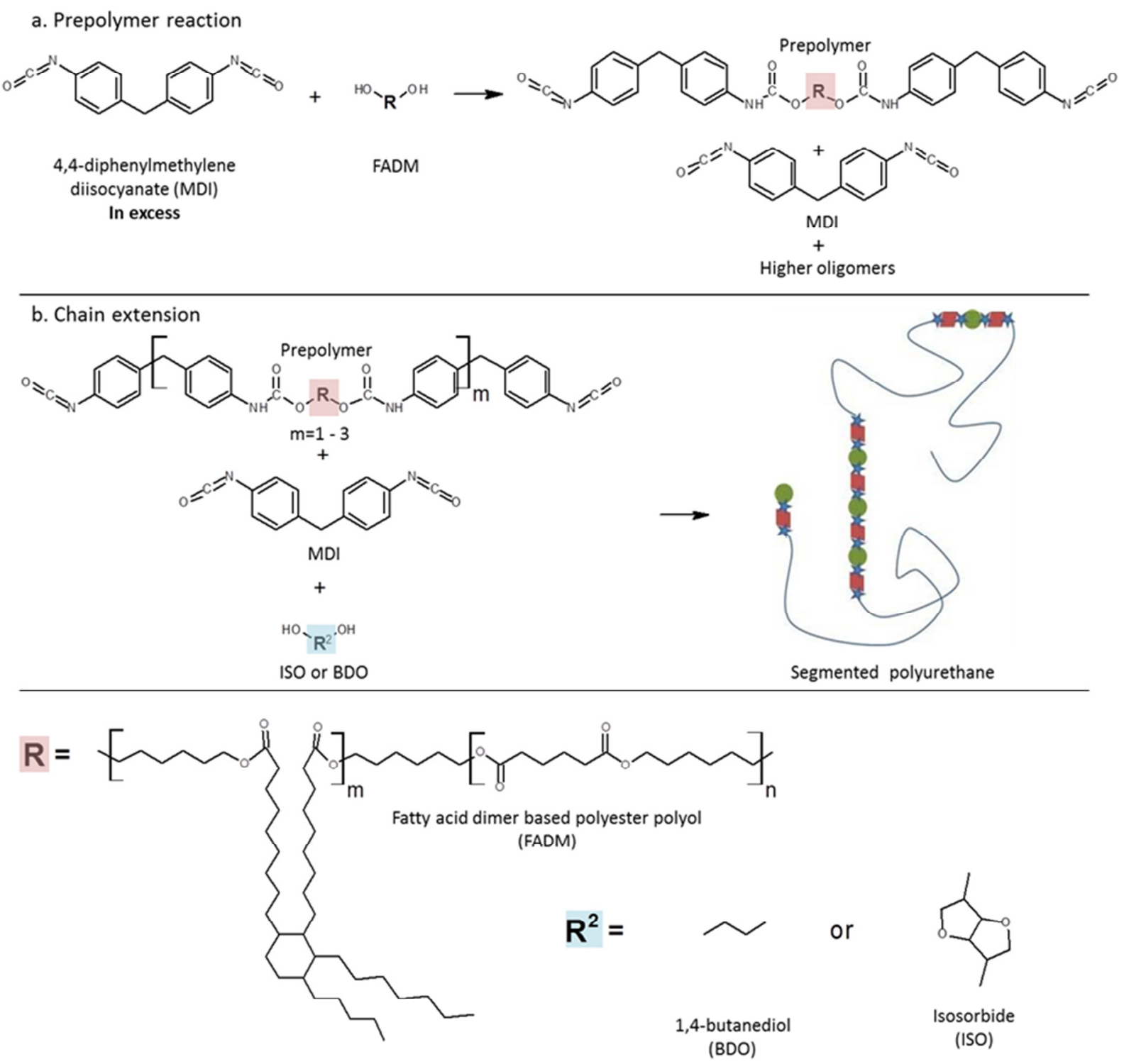

\section{Scheme 1: Preparation of NCO-terminated prepolymers and thermoplastic polyurethanes}

The synthesis was optimized in order to obtain polymers with sufficiently high molar masses to allow a subsequent correct assessment of their physical properties. In a first step, a prepolymer was obtained by reaction of the polyol with an excess of MDI for $45 \mathrm{~min}$, under vacuum, in a reactor equipped with mechanical stirring and an inlet for nitrogen flushing, with an oil bath at $80^{\circ} \mathrm{C}$. The 
chain extender was subsequently added, in liquid state with a syringe, either at room temperature in the case of BDO or at $80^{\circ} \mathrm{C}$ in the case of ISO. For ISO-based compositions, DBTDL catalyst was used. A solution of $0.07 \mathrm{wt} \%$ of DBTDL was made in the melted ISO. The reaction was then performed at $80^{\circ} \mathrm{C}$ under vacuum with mechanical stirring until a clouding in the reaction mixture was observed, indicating the beginning of phase segregation. At this point the viscous polymer liquid was poured from the reactor into molds to form either $2 \mathrm{~mm}$-thick square sheets, or $10 \mathrm{~mm}$-thick cylinders. Sheets were placed at $110^{\circ} \mathrm{C}$ under a 10 bar pressure for 2 hours before being moved to an oven $\left(110^{\circ} \mathrm{C}\right)$ for $16 \mathrm{~h}$. Cylinders were simply placed in the oven at $110^{\circ} \mathrm{C}$ for $18 \mathrm{~h}$ (higher curing temperatures cannot be considered given the thermal reversibility of the urethane bond). Samples were then removed from the oven and left to cool on ceramic benches with unopened molds. When cooled, molds were finally opened to obtain $150 \times 150 \times 2 \mathrm{~mm}$ polymer sheets

\subsection{Characterization methods}

Proton $1 \mathrm{H}$ NMR spectroscopy was used to study the structure and composition of the fatty acid dimer based macrodiol, as well as a mean to monitor synthesis. The $1 \mathrm{H}$ spectra were recorded at $400 \mathrm{MHz}$, in deuterated chloroform ( $\left.\mathrm{CDCl}_{3}\right)$ with a Bruker Avance III $400(5 \mathrm{~mm})$, at $298 \mathrm{~K}$, acquisition time $2 \mathrm{~s}$, pulse delay $4 \mathrm{~s}$, and 128 scans.

Size Exclusion Chromatography was performed in a $0.01 \mathrm{M}$ solution of bis(trifluoromethane) sulfonimide lithium salt $\left(\mathrm{LiNTf}_{2}\right)$ in dimethylformamide (DMF) at $50^{\circ} \mathrm{C}$ as the eluent, using a Viscotek pump (VE 1122 solvent delivery and VE 5111 Injector Value Bracket), and differential refractive index (RI) detector (Viscotek VE $3580 \mathrm{RI}$ detector). Three porous styrene-divinylbenzene copolymer columns from Malvern, with porosity $10^{3}, 10^{5}$ and $10^{3} \AA$, including a precolumn, were used at a flow rate of $1.0 \mathrm{~mL} / \mathrm{min}$. Conventional calibration used polystyrene standards from Shodex. Polymer solution concentration was $3 \mathrm{mg} \cdot \mathrm{mL}^{-1}$. Injection volumes were $100 \mu \mathrm{L}$. The sample solutions in DMF were prepared 14 days prior to the measurement in order to obtain a good solubility. Sample solutions were filtered through $0.2 \mu \mathrm{m}$ porous PTFE membranes prior to measurement. Concentration of free MDI in the prepolymer was obtained by using the refractometric detector, by comparison with a calibration curve of the MDI RI peak area as a function of the MDI concentration in THF.

Thermal behavior was assessed by means of a TA Instruments DSC Q20 equipment, calibrated with Indium standards. Samples of 3 to $5 \mathrm{mg}$ were sealed in hermetic aluminum pans. They were subjected to a first cooling stage from room temperature to $-150^{\circ} \mathrm{C}$, followed by a first heating ramp from $-150^{\circ} \mathrm{C}$ to $250^{\circ} \mathrm{C}$. A second cycle of cooling and heating in the $-150^{\circ} \mathrm{C}$ to $250^{\circ} \mathrm{C}$ temperature range was performed additionally. All steps were carried out at $20^{\circ} \mathrm{C}$.min- 1 under helium (flow rate $\left.25 \mathrm{~mL} \cdot \mathrm{min}^{-1}\right)$.

Dynamic mechanical analysis (DMA) was performed on an ARES G2 rheometer from TA Instruments, with temperature scans of $3^{\circ} \mathrm{C} \cdot \mathrm{min}^{-1}$ from $-100^{\circ} \mathrm{C}$ to $180^{\circ} \mathrm{C}$. Rectangular samples of average $2.5 \times 11 \times 7 \mathrm{~mm}$ were cut from bulk sheet samples and used to perform rectangular torsion tests. Parameters were set such that frequency was $1 \mathrm{~Hz}$, and strain was $0.01 \%$.

Hardness tests were performed with a manual Shore D durometer from Zwick-Roell on $10 \mathrm{~mm}$-thick cylindrical bulk samples, following standard DIN 53505. Shore D hardness was determined at room temperature, as the average of fifteen measurements, spaced by at least $5 \mathrm{~mm}$ and at a margin of $5 \mathrm{~mm}$ from the edges of the sample. 
Electron transmission microscope samples were prepared by cryo-ultramicrotomy at $-100^{\circ} \mathrm{C}$. The obtained ultrathin sections of $80 \mathrm{~nm}$ were observed using a PHILIPS CM120 transmission electron microscope (TEM) at an acceleration voltage of $120 \mathrm{KV}$.

Atomic Force Microscopy (AFM) allowed observing phase contrast images of the smooth flat surfaces obtained by cryo-ultramicrotomy. Scans were performed in tapping mode on a Nano-observer CSInstruments equipped with a cantilever with a stiffness of $40 \mathrm{~N} / \mathrm{m}$ and a resonance frequency of $300 \mathrm{KHz}$ purchased from APPNANO. A setpoint of $6 \mathrm{~V}$ was used in order to increase the oscillation amplitude of the cantilever. This resulted in more contrast on the phase image at the expense of the topography image.

Compression set tests were made after standard NF ISO 815-1 and were performed with a simple apparatus made of two square steel plates separated by two steel spacers of dimensions $9.40 \times 20 \times 200 \mathrm{~mm}$. Samples were obtained by piling 6 discs of diameter $29 \mathrm{~mm}$, cut in the $2 \mathrm{~mm}$ TPU sheets. The apparatus was placed in a stove at $70^{\circ} \mathrm{C}$ for $24 \mathrm{~h}$, at which point the samples were taken out of the stove and released from the apparatus. After $30 \mathrm{~min}$, the final thickness was measured. More information about this particular measurement can be found in the Supplementary Content.

Swelling in water tests were conducted on samples of around $20 \times 20 \times 2 \mathrm{~mm}$, which were weighed and submerged in separated bottles containing around $40 \mathrm{~mL}$ de-ionized water at room temperature. They were then periodically taken out, dried on paper towel and weighed in order to plot water uptake over time.

\section{Results and discussion}

\subsection{Polyurethanes synthesis and physico-chemical characterization}

A prepolymer with an excess of NCO functions was synthesized by reacting FAMD with an excess of MDI in bulk, producing sample named FADM-pp. The prepolymer composition is reported in Table 1. The prepolymers FADM-pp and the corresponding pure macrodiol (named FADM) were characterized by Size Exclusion Chromatography (SEC) in THF in order to obtain average molar masses and percentage of remaining free MDI. Results are reported in Table 1 as well.

Table 1: Macrodiol and prepolymer composition and molar mass

\begin{tabular}{cccccccc}
\hline Sample & $\begin{array}{c}\text { Polyol } \\
\text { mass }(\mathbf{g})\end{array}$ & $\begin{array}{c}\text { MDI } \\
\text { mass }(\mathbf{g})\end{array}$ & NCO/OH ratio & $\begin{array}{c}\text { Free MDI } \\
\text { percentage } \\
(\mathbf{m o l})\end{array}$ & $\begin{array}{c}\mathbf{M}_{n} \\
\left(\mathbf{g} \cdot \mathbf{m o l}^{-1}\right)\end{array}$ & $\begin{array}{c}\mathbf{M}_{\mathbf{w}} \\
\left(\mathbf{g} \cdot \mathbf{m o l}^{-1}\right)\end{array}$ & $\begin{array}{c}\mathbf{D} \\
\left(\mathbf{M}_{\mathbf{w}} / \mathbf{M}_{\mathbf{n}}\right)\end{array}$ \\
\hline FADM & - & - & - & 0 & $3,760 \pm 370$ & $6,650 \pm 660$ & 1.8 \\
FADM-pp & 26.91 & 10.57 & 3.203 & 37.3 & $4,040 \pm 400$ & $8,970 \pm 900$ & 2.2
\end{tabular}

As the calibration used is the conventional method with polystyrene standards, the macrodiol's average molar mass is higher than the value of $M_{n}=2,200 \mathrm{~g} \cdot \mathrm{mol}^{-1}$ given by the suppliers. Given the complexity of this polyol structure, it is difficult to precisely calculate this molar mass from the ${ }^{1} \mathrm{H}$ NMR spectrum; however assuming a difunctional molecule, this grossly estimated value (slightly below 2,000 g.mol ${ }^{-1}$ ) would nevertheless be closer to that deduced from the hydroxyl number 
$\left(2,020\right.$ g. mol $\left.{ }^{-1}\right)$ than from these SEC results. However this technique interestingly reveals that the molar mass dispersity of the samples is impacted by the MDI functionalization: the value of $\emptyset$ is increasing between FADM and FADM-pp.

Following the characterization of the prepolymers, batches of TPUs were synthesized by reaction with chain extenders isosorbide (ISO) and 1,4-butanediol (BDO). Table 2 reports the compositions and names of the studied samples along with their hard segments (HS) weight percent content and molar mass. A simple calculation shows that the biobased content of all the samples based on FADM and ISO lies around 37 to $38 \mathrm{wt} \%$, i.e. a rather high value compared to traditional elastomers that are often $100 \%$ petro-based.

The prepolymer was reacted with either ISO or BDO to act as a model. The visual aspect of the samples is presented in Figure 2. Translucence increases as HS ratio decreases.

Table 2: Composition and molar mass of fatty acid dimers polyester (FADM)-based polyurethanes obtained by SEC in LiNTf $f_{2} 0.01 \mathrm{M}$ solution at $1 \mathrm{~mL} / \mathrm{min}$ and calculated from polystyrene standards

\begin{tabular}{lcccccc} 
Sample & $\begin{array}{c}\text { Chain } \\
\text { extender }\end{array}$ & \%wt HS & $\begin{array}{c}\text { Stoichiometry } \\
\text { Ss/MDI/Diol }\end{array}$ & $\begin{array}{c}\mathbf{M}_{\mathbf{n}} \\
\left(\mathbf{k g} \cdot \mathbf{m o l}^{-1}\right)\end{array}$ & $\begin{array}{c}\mathbf{M}_{\mathbf{w}} \\
\left(\mathbf{k g} \cdot \mathbf{m o l}^{-1}\right)\end{array}$ & $\begin{array}{c}\mathbf{0} \\
\left(\mathbf{M}_{\mathbf{w}} / \mathbf{M}_{\mathbf{n}}\right)\end{array}$ \\
\hline FMI25 & ISO & 24 & $1: 2: 1$ & $39.0 \pm 4$ & $120 \pm 12$ & 3.1 \\
FMI35 & ISO & 34 & $1: 3: 2$ & $18.1 \pm 2$ & $56.5 \pm 6$ & 3.1 \\
FMI40 & ISO & 42 & $1: 4: 3$ & $15.9 \pm 2$ & $50.2 \pm 5$ & 3.2 \\
FMI50 & ISO & 53 & $1: 6: 5$ & $11.6 \pm 1$ & $40.7 \pm 4$ & 3.5 \\
FMB25 & BDO & 23 & $1: 2: 1$ & $34.1 \pm 3$ & $90.1 \pm 9$ & 2.6 \\
FMB35 & BDO & 32 & $1: 3: 2$ & $30.3 \pm 3$ & $97.5 \pm 10$ & 3.2 \\
FMB40 & BDO & 39 & $1: 4: 3$ & $23.5 \pm 2$ & $76.1 \pm 8$ & 3.2 \\
FMB50 & BDO & 49 & $1: 6: 5$ & $18.1 \pm 2$ & $60.4 \pm 6$ & 3.3 \\
\hline
\end{tabular}



Figure 2: Visual appearance of the $2 \mathrm{~mm}$ thick sample sheets. First row: FMB sample series Second row: FMI sample series. HS ratio increases from left to right 
All the samples displayed a yellow hue originating from the initial FADM color. Overall, the average molar mass is at least $11 \mathrm{~kg} \cdot \mathrm{mol}^{-1}$, with an average around $20 \mathrm{~kg}^{\mathrm{mol}}{ }^{-1}$. It can be noted that the dispersity is globally high with values almost always over 3.0. Moreover, it is obvious that the curves shown in Figure 3 are shifted toward the higher retention volumes as the fraction of hard segment increases on the FMB sample series. A clear trend can be observed: an increase in fraction of hard segments is linked to a decrease in the molar mass of both series based on ISO and BDO (Table 2), which is in accordance with the results of several other studies on isosorbide (Park et al., 2013; Kim et al., 2014; Oh et al., 2015) and BDO (Bueno-Ferrer et al., 2012b) Moreover, in the case of the samples based on ISO, the increase in hard segment content is linked to the stagnation of the higher mass fraction values and the appearance of a small shoulder at the higher retention volumes that probably originates from pure hard segments that are not bound to any FADM soft segment and have a pronounced effect on the value of $M_{n}$ and dispersity for those materials. This difference is attributed to the diminished reactivity of the hydroxyl functions of isosorbide.
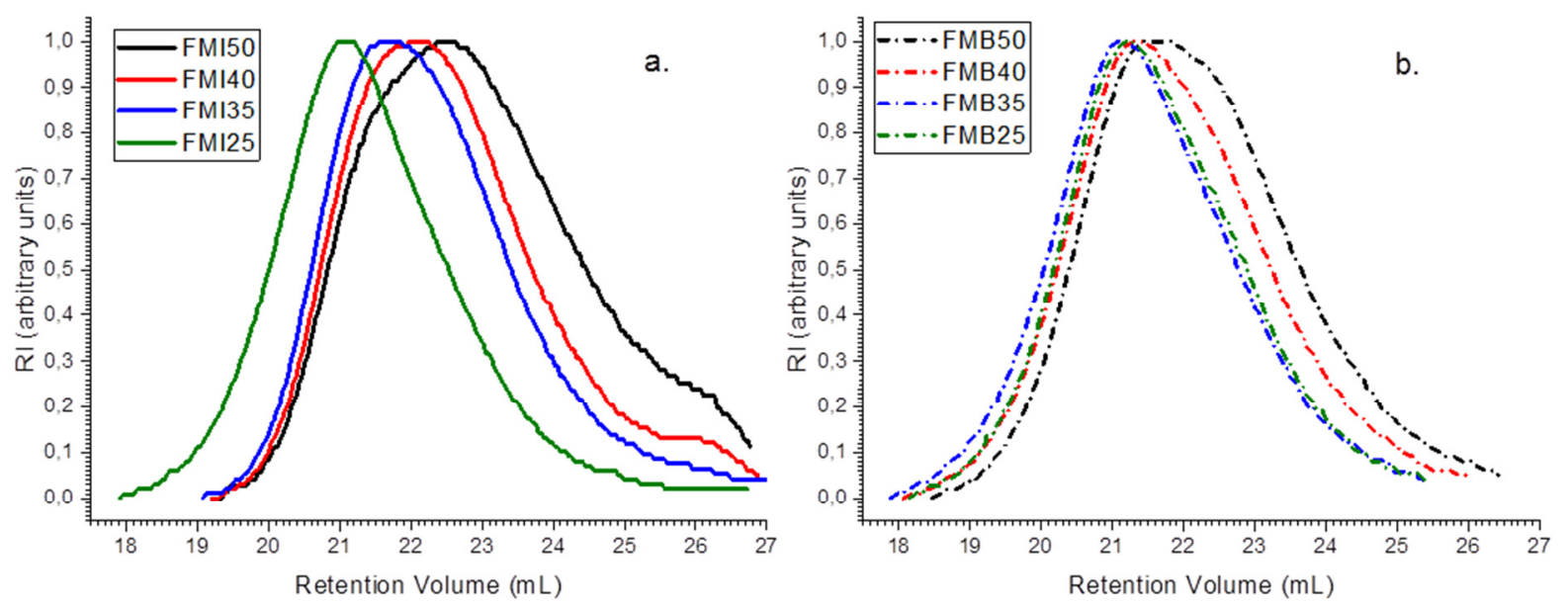

Figure 3: SEC curves of FADM based polyurethanes, in DMF 0.01 LiNTf2 - a. with ISO as the chain extender $-b$. with BDO as the chain extender.

\subsection{Influence of isosorbide on the thermomechanical behavior of the urethane elastomers}

Further measurements were carried out on the TPU samples. First the Shore D hardness was plotted as a function of the HS weight ratio in Figure 4a. Overall, the samples based on ISO display a slight increase in hardness with respect to their BDO-based counterpart, in the order of magnitude of 5 to 10 Shore $D$ units. This could be explained by a difference in phase segregation dependent on both chemical natures of the polyurethane blocks and on the thermal history (Yilgör et al., 2015). From the compression set results presented in Figure $4 b$, the use of isosorbide chain extender seems to be favorable to a better shape retention compared to BDO. The difference between the two is however slight. Those results could be better understood by studying the thermal behavior. 

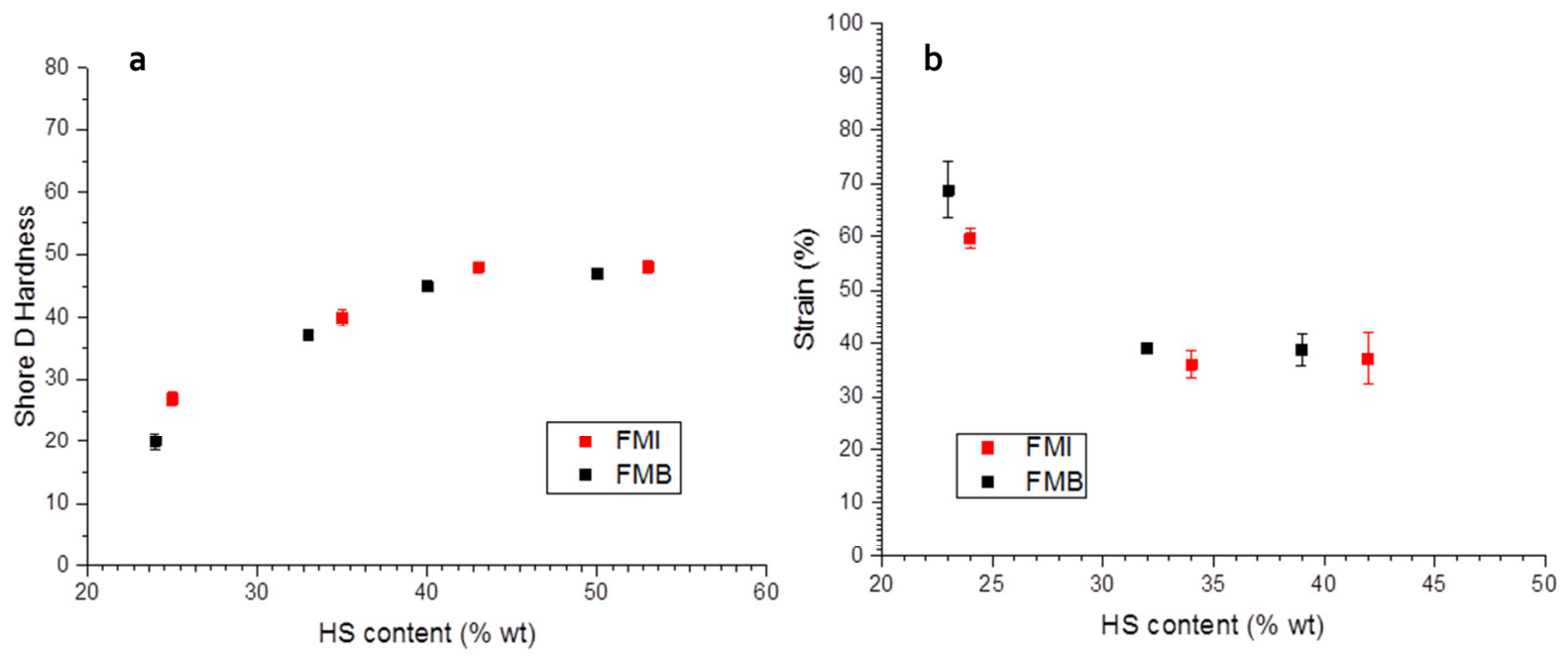

Figure 4: (a) Shore D hardness and (b) Compression set results of TPU as a function of the HS weight content and sample composition

Using DSC, the glass transition temperature of the isosorbide-based series of samples FMI25, FMI35, $\mathrm{FMI} 40$ and FMI50 was measured around $-45^{\circ} \mathrm{C}$ and was not influenced by the hard segment content, as can be seen in Figure 5a. All samples are thus phase-segregated. The length and concentration of the HS influences the minimum melting peak of the HS crystals: the temperature of the extremum is increasing from $197^{\circ} \mathrm{C}$ to $208^{\circ} \mathrm{C}$ for the isosorbide-based samples. It can be noted as well that no crystallization was obtained on the FMI 25 sample. The presence of the HS phase can be only seen by a glass transition at $140^{\circ} \mathrm{C}$.
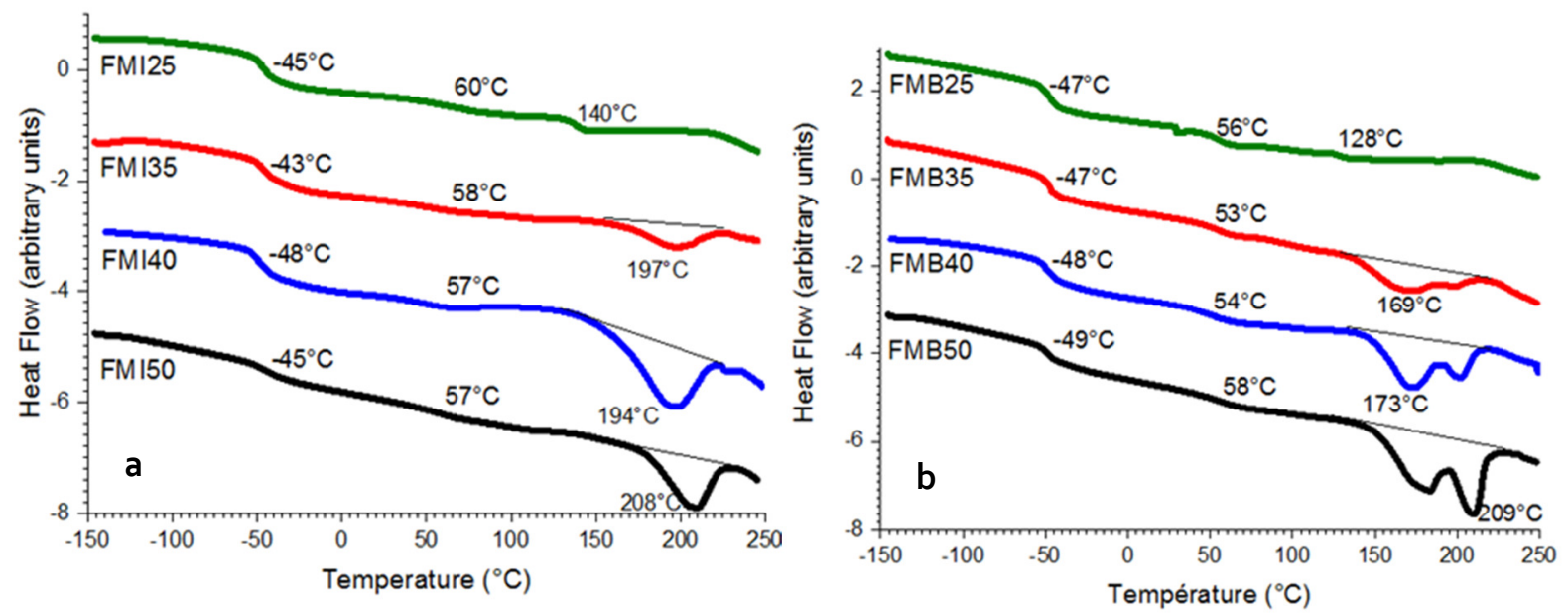

Figure 5: Differential Scanning Calorimetry, first heating ramp measured at $20^{\circ} \mathrm{C} / \mathrm{min}$ from $-150^{\circ} \mathrm{C}$ to $250^{\circ} \mathrm{C}$ for the sample series based on (a) ISO; (b) BDO

This low value considering the $\mathrm{Tg}$ of the pure MDI/ISO HS which is around $187^{\circ} \mathrm{C}$ (Cognet-Georjon et al., 1995) could originate from a HS-rich phase mixed to some soft phase, or shorter HS, as the HS average length is getting lower for low HS content (Peebles, 1974, 1976), or a mix of both situations. Lastly, an intermediate secondary transition appears quite stable as well with the hard segment content: it can be found around $55^{\circ} \mathrm{C}$ for all eight isosorbide-based and BDO-based samples. It is not 
present in the second heating cycle performed on the samples. In the case of the BDO-based series of samples shown in Figure $5 b$, the glass transition temperature is not influenced by the hard segment concentration. The melting peak extremum temperature in the case of the model BDObased samples is increasing as well with the hard segment concentration. Overall, from DSC curves, the behavior of isosorbide-based samples is remarkably similar to that of the model BDO-based samples. From Table 3, it can also be noted that all eight samples of the FADM-based series display a rather stable Tg throughout the heating cycles, which is an indicator of a kinetically favorable and stable phase segregation. ISO-based series of samples displays a slight increase in the $\mathrm{Tg}$ on the second heating cycle compared to BDO.

Table 3: Summary of the DSC results for the sample series based on FADM

\begin{tabular}{|c|c|c|c|c|c|}
\hline \multirow{2}{*}{ Sample } & \multicolumn{3}{|c|}{$1^{\text {st }}$ Heating Cycle } & \multicolumn{2}{|c|}{$2^{\text {nd }}$ Heating Cycle } \\
\hline & $\mathrm{T}_{\mathrm{g}}^{\mathrm{SP}}$ a) $\left({ }^{\circ} \mathrm{C}\right)$ & $\mathrm{T}_{\mathrm{g}}^{\mathrm{HP}}\left({ }^{\circ} \mathrm{C}\right)$ & $\mathrm{T}_{\mathrm{f}}\left({ }^{\circ} \mathrm{C}\right)$ & $\mathrm{T}_{\mathrm{g}}\left({ }^{\circ} \mathrm{C}\right)$ & $\mathrm{T}_{\mathrm{f}}\left({ }^{\circ} \mathrm{C}\right)$ \\
\hline FMI25 & -45 & 140 & - & -42 & - \\
\hline FMI35 & -43 & - & 197 & -43 & - \\
\hline FMI40 & -48 & - & 194 & -44 & - \\
\hline FMI50 & -45 & - & 208 & -41 & 219 \\
\hline FMB25 & -47 & 128 & - & -47 & - \\
\hline FMB35 & -47 & - & 169 & -48 & 167 \\
\hline FMB40 & -48 & - & 173 & -48 & 187 \\
\hline FMB50 & -49 & - & 209 & -50 & 209 \\
\hline
\end{tabular}

a) Glass transition of the soft phase - b) Glass transition of the hard phase

Samples FMB35, FMB40 and FMB50 presented in Figure 5b, display a complex series of endothermal phenomena at high temperature (above $\sim 130-150^{\circ} \mathrm{C}$ ). Studies on such thermal behaviors showed a large influence of thermodynamic and structural parameters (Koberstein and Galambos, 1992; Saiani et al., 2001, 2004, 2007; Fernández-d'Arlas et al., 2016). Multiple melting endotherms (MME) can be due to distinct crystal populations with different melting temperatures linked to thermal history (Koberstein and Galambos, 1992, Fernández-d'Arlas et al., 2016) and DSC cooling and heating rates (Balko et al., 2017). However, for high HS content, it was shown that MME were due to soft segment rich-micro-domains appearing in a hard ordered phase (Saiani et al., 2001, 2004, 2007) in model materials based on polypropylene oxide/MDI/BDO upon slow heating, and they tended to be absent upon fast heating (Balko et al., 2017). The appearance of MME at temperatures over $200^{\circ} \mathrm{C}$ in PTMEG/MDI/BDO systems was attributed (Li et al., 2012) to the melting of ordered HS followed by the melting of microcrystalline HS domains. All samples presented here were subjected to the same thermal treatment during synthesis, and as such were all annealed for the same time and 
temperature. However, re-crystallization during cooling $\left(20^{\circ} \mathrm{C} / \mathrm{min}\right)$ and melting during the second heating scan are clearly observed only for a HS concentration over $40 \mathrm{wt} \%$ for ISO-based samples, while this limit is as low as $25 \mathrm{wt} \%$ for their BDO-based counterparts. The occurrence of this phenomenon in samples containing BDO supports the fact that MDI/BDO HS does separate and crystallize more easily from the FADM soft segment than MDI/ISO. In order to further characterize the thermal behavior, both series of FADM-based materials were tested with DMA. The obtained curves are presented in Figure 6 and Figure 7, and some numerical values are reported in Table 4 for ease of reading purposes.

Table 4: Summary of DMA results for the sample series based on FADM

\begin{tabular}{|c|c|c|c|c|c|c|c|}
\hline \multirow{2}{*}{ Sample } & \multirow{2}{*}{$\mathbf{T}_{\alpha}$} & \multicolumn{3}{|c|}{$\mathbf{2 5}^{\circ} \mathrm{C}$} & \multicolumn{3}{|c|}{$\mathbf{T}_{\alpha}+50^{\circ} \mathrm{C}$} \\
\cline { 3 - 8 } & $\left.\mathbf{l}^{\circ} \mathbf{C}\right)$ & $\mathbf{G}^{\prime}(\mathrm{MPa})$ & $\mathbf{G}^{\prime \prime}(\mathrm{MPa})$ & $\tan \delta$ & $\mathbf{G}^{\prime}(\mathrm{MPa})$ & $\mathbf{G}^{\prime \prime}(\mathrm{MPa})$ & $\tan \delta$ \\
\hline FMI25 & -31 & 5.5 & 0.6 & 0.11 & 5.4 & 0.7 & 0.13 \\
FMI35 & -32 & 19 & 2.4 & 0.13 & 21 & 2.7 & 0.13 \\
FMI40 & -34 & 46 & 4.7 & 0.10 & 51 & 5.8 & 0.11 \\
FMI50 & -35 & 100 & 9.0 & 0.09 & 114 & 11 & 0.10 \\
FMB25 & -33 & 4.9 & 0.5 & 0.10 & 5.3 & 0.6 & 0.11 \\
FMB35 & -35 & 12 & 0.9 & 0.08 & 13 & 1.1 & 0.09 \\
FMB40 & -36 & 25 & 2.0 & 0.08 & 28 & 2.5 & 0.09 \\
FMB50 & -37 & 82 & 5.7 & 0.07 & 93 & 8.3 & 0.09 \\
\hline
\end{tabular}




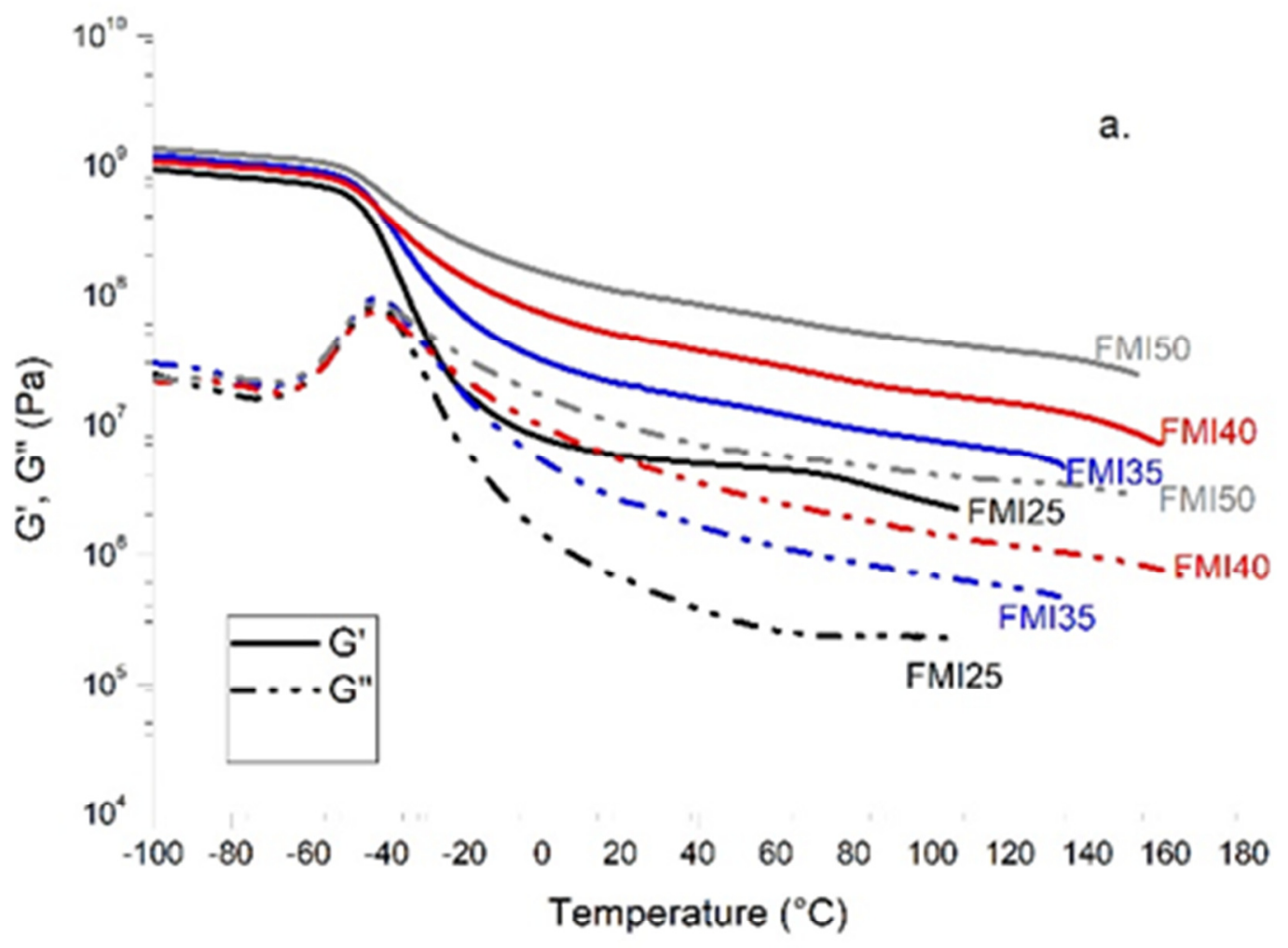

0.6

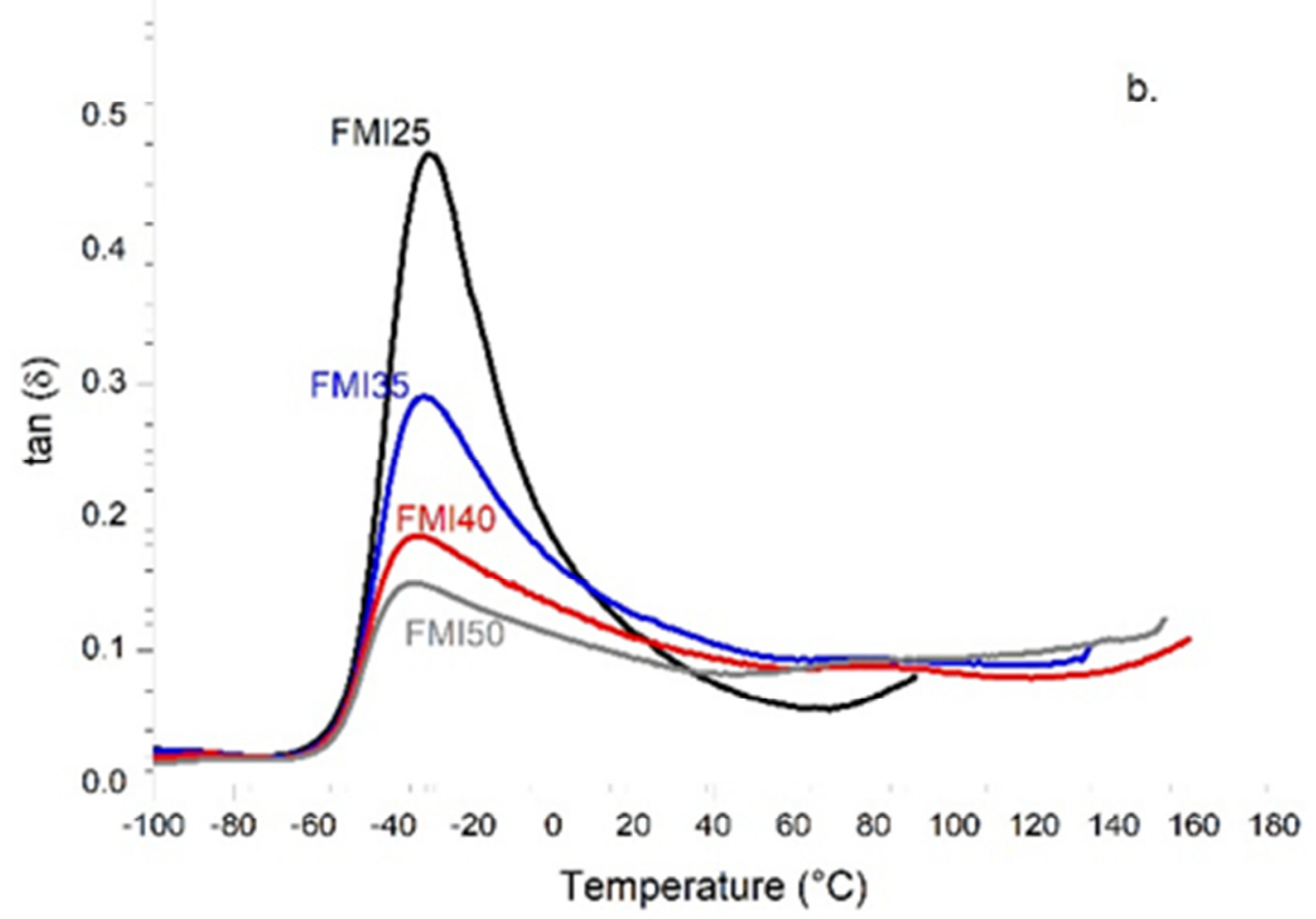

Figure 6: Dynamic Mechanical Analysis of FADM and ISO-based samples FMI25, FMI35, FMI40 and FMI50, at a frequency of $1 \mathrm{~Hz}$ and $0.1 \%$ strain, with a heating ramp of $3^{\circ} \mathrm{C} / \mathrm{min}-a$. Storage $\left(G^{\prime}\right)$ and loss $\left(G^{\prime \prime}\right)$ moduli - b. Loss factor (tan $\left.\delta\right)$ 

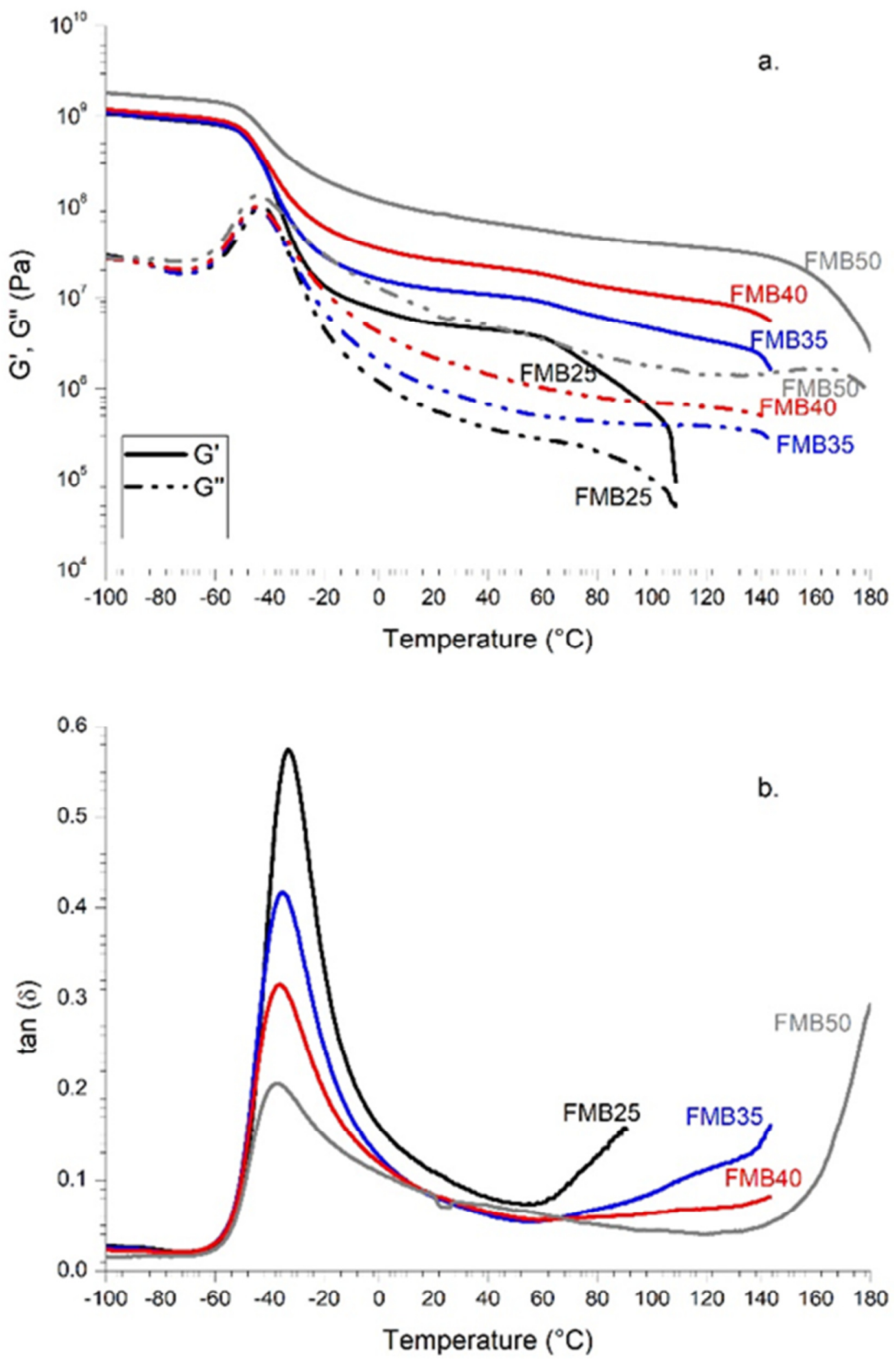

Figure 7: Dynamic Mechanical Analysis of FADM and BDO-based samples FMB25, FMB35, FMB40 and FMB50, at a frequency of $1 \mathrm{~Hz}$ and $0.1 \%$ strain, with a heating ramp of $3^{\circ} \mathrm{C} / \mathrm{min}-a$. Storage $\left(G^{\prime}\right)$ and loss $\left(G^{\prime \prime}\right)$ moduli $-b$. Loss factor (tan $\delta$ ) 
Overall, the DMA results are consistent with the results obtained by DSC. Again all the materials appear clearly phase-separated, with a first $\alpha$ relaxation well below room temperature. The values of the plateaus and Ta temperatures are very similar for ISO and BDO sample series, in spite of the lower molar masses induced by ISO. Figure 6 presents the DMA curves of the isosorbide and FADMbased samples. The temperature at the maximum of $\tan \delta$ of the soft phase is very stable. However, the peak maximum decreases (from $\tan \delta=0.47$ to 0.15 ) and it is as well becoming broader as the HS content increases from 25 to $50 \mathrm{wt} \%$; and it is almost transforming into a plateau for samples FMI40 and FMI50. The flow limit onset of the isosorbide-based series could not be obtained because the samples broke before it was reached. Figure 7 presents the DMA of the BDO-based models. It can be noted that the $\alpha$ transition temperature is also very stable as the HS fraction increases. As the HS content increases, the rubber plateau is becoming less defined and the T $\alpha$ transition broadens for both ISO and BDO. The flow limit onset was only obtained for the FMB50 sample as the other samples of the series broke earlier. Finally it can be noticed that the rubber moduli (or $\mathrm{G}^{\prime}$ measured at $\mathrm{T}_{\alpha}+50^{\circ} \mathrm{C}$, Table 4) are generally higher for ISO-based materials than for their BDO-counterparts.

The second transition found in the DSC curves between $50^{\circ} \mathrm{C}$ and $70^{\circ} \mathrm{C}$ in both series of samples can be seen on the DMA curves of the BDO-based series. It appears as a small inflection of $\mathrm{G}^{\prime}$ and $\mathrm{G}^{\prime \prime}$ in the same range of temperature on FMB40 and FMB35 samples. This inflection is not as visible for the isosorbide-based series but may also be present. A wide array of physical phenomena could be behind this transition, including the $\mathrm{Tg}$ of a hard phase, $\mathrm{H}$-bond interactions or annealing-induced order. This transition cannot be attributed solely to the hard domains of pure HS, as the glass transition of such HS was found for BDO/MDI to be around $100-110^{\circ} \mathrm{C}$ (Cuvé et al., 1992) and for $\mathrm{MDI} / \mathrm{ISO}$ around $187^{\circ} \mathrm{C}$ (Cognet-Georjon et al., 1995) Moreover, partial crystallization of the soft phase occurs for segment lengths starting at 2000 g.mol-1 and above (Klinedinst et al., 2012). However, the appearance of an amorphous interphase composed of a mix of some hard segments with soft segments cannot be ruled out. It was also mentioned (Yilgör et al., 2015) that the breakage of hydrogen bonds between urethanes $-\mathrm{NH}$ and the oxygens of the ether or ester carbonyl groups from the soft segments could occur in the same temperature ranges; carbonyls are indeed found in FADM. Such $\mathrm{H}$ bonds were shown (Christenson et al., 1986) to disappear and to be replaced by $\mathrm{H}$ bonds between urethane $-\mathrm{NH}$ and- $\mathrm{CO}$ groups when the phase segregation increased. For the moment, the exact nature of this transition is unresolved. It is however interesting to note that its temperature of appearance seems to be related to the HS nature as it is slightly higher for ISO than for BDO based samples.

More information was gathered by performing TEM on some samples (see Figure 8). The FMB35 sample is displaying a continuous soft phase (light contrast) and globular hard phase domains (dark contrast, around 2-3 $\mu \mathrm{m}$ diameter). By comparison, FMI35 is also displaying those features, but the 2 $\mu \mathrm{m}$ hard phase domains have more homogeneous size dispersion and are stacked in a hexagonal-like fashion. This stacking is even more obvious and regular for FMI40, which features smaller domains (around $1.2 \mu \mathrm{m}$ diameter). The FMI50 is still displaying a continuous soft phase with hard phase domains. However, the hard phase domains seem to be in a coalescing dynamic, with very huge domains (up to $10 \mu \mathrm{m}$ diameter) and broad size dispersion, suggesting that the system is getting close to phase inversion. 

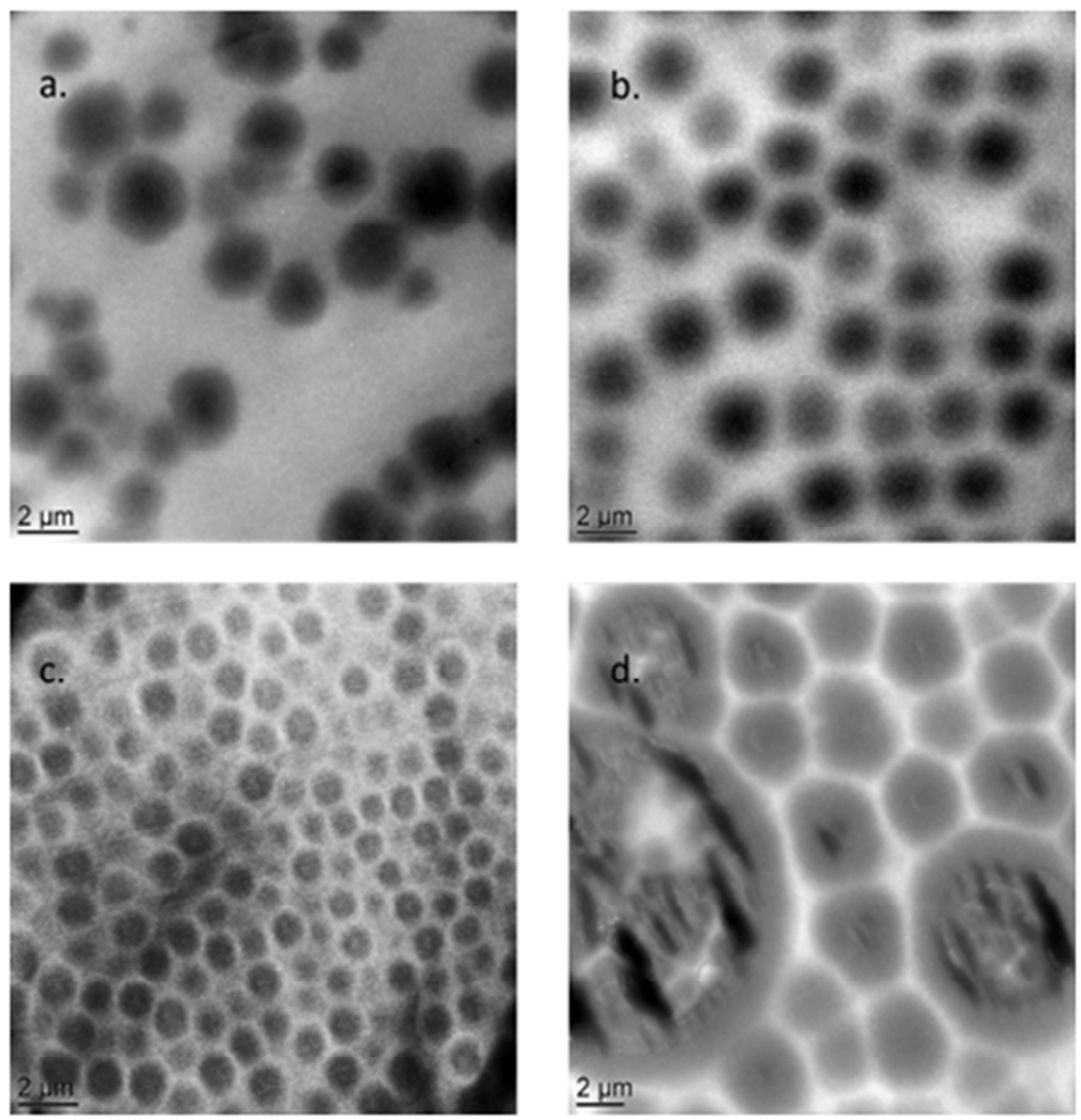

Figure 8: TEM images on cryo-microtomy films a. FMB35 - b. FMI35 - c. FMI40 - d. FMI50

Similar morphologies were observed on AFM phase images, shown in Figure 9. By comparison, the morphology of sample FMI25 is closer to FMB35 than the latter is to FMI35 in term of hard domains volume concentration. Rays on the images a. to $d$. are artifacts originating from the preparation method. 

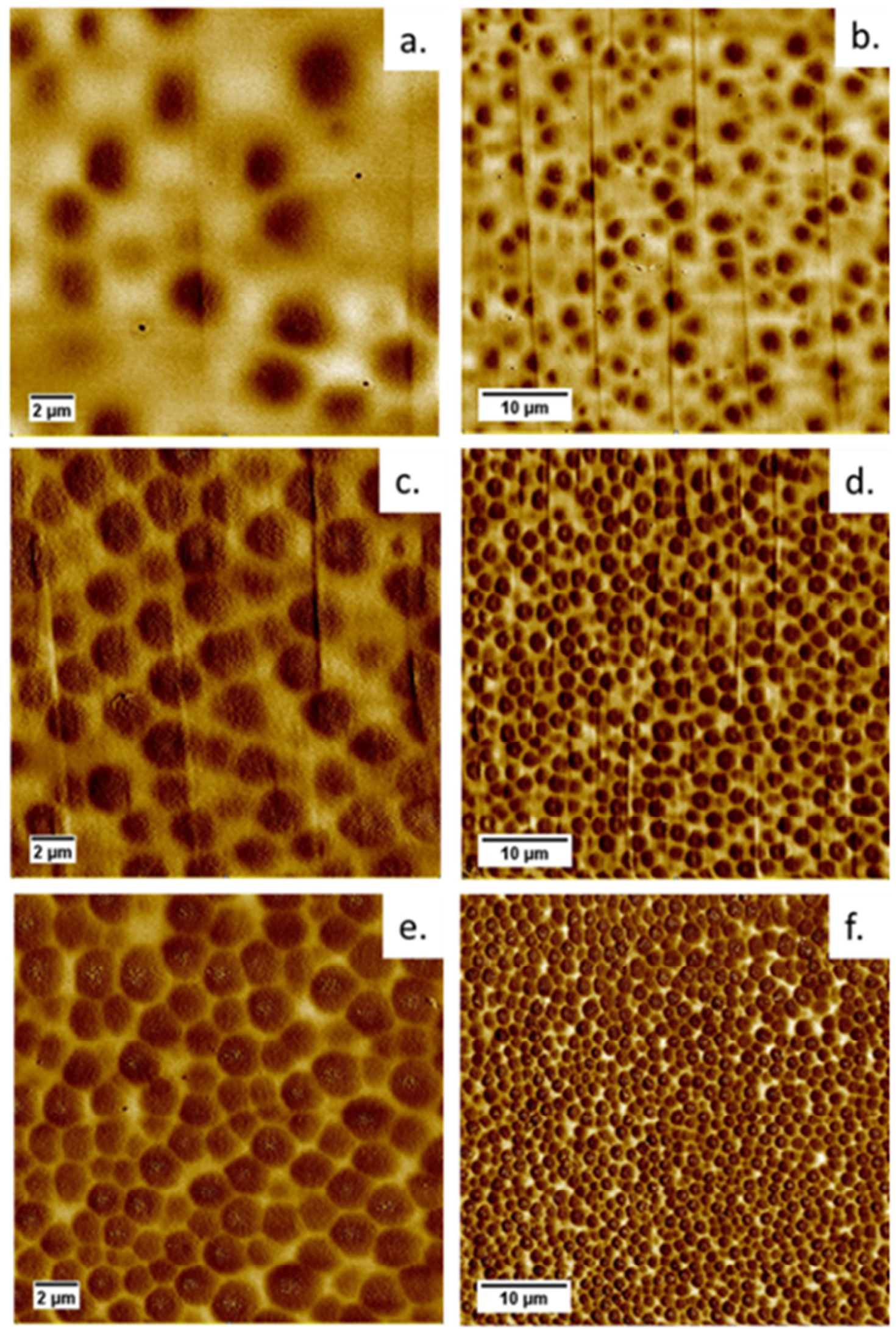

Figure 9: AFM images on cryo-microtomy surfaces at two different magnifications (first row:

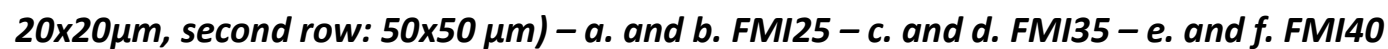


Lastly, water uptake as a function of time was measured for samples FMI35, FMI50 and FMB35 and FMB50 (see Figure 10). First of all, one can note that the water uptake over the course of 50 days was always under $1 \mathrm{wt} \%$, and that the uptake of isosorbide-based sample is on average only superior to the model BDO-based samples by $25 \%$. By comparison of FMI50 and FMI35, one can also see that the HS content has an influence on the water uptake, as MDI/ISO HS tend to be more hygroscopic than the FADM SS. However, even if pure isosorbide is highly hygroscopic; it does not induce a large water uptake compared to model chain extenders, when in combination with a hydrophobic soft segment such as FADM. Water uptake is decreasing on FMI35 and FMB35 curves after 35 days, which might be due to a mass loss from the start of hydrolysis of the ester functions of the FADM soft segment.

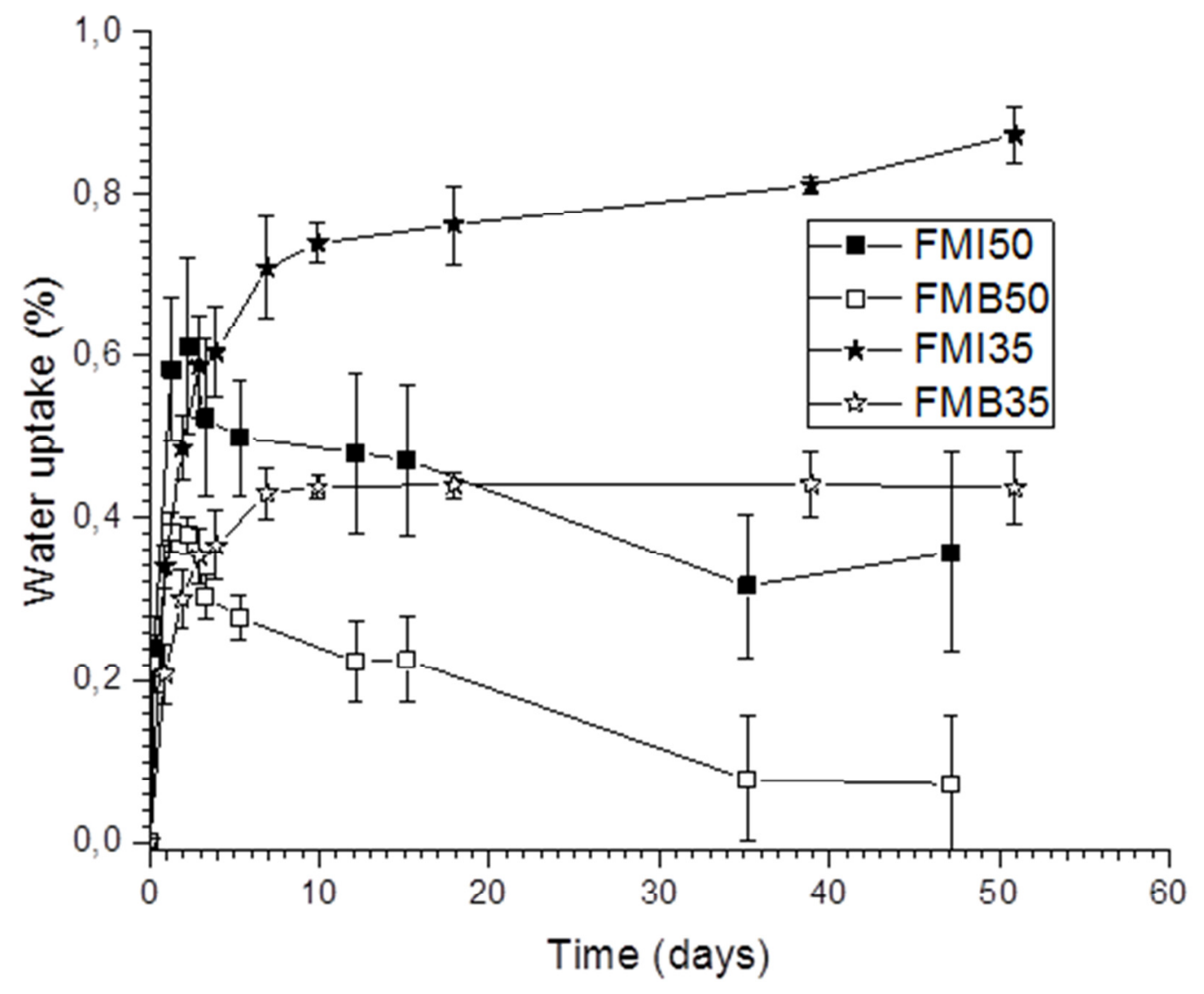

Figure 10: Swelling in water as a function of time and TPU composition

\section{Conclusion}

In this work, novel thermoplastic polyurethanes based on bio-based isosorbide, ISO or 1,4butanediol, BDO, and a fatty acid dimer-based polyester derived from rapeseed oil, FADM, were investigated. Several HS contents were compared and in every instance the TPUs were successfully obtained by a two-step synthesis. In a first part, the prepolymers prepared were carefully characterized in order to validate the synthesis protocol. They were subsequently used for TPU synthesis. The lower reactivity of ISO sometimes induces lower molar masses. TPUs obtained from ISO were then systematically compared to models based on BDO, and in spite of their slightly lower molar masses were found to display a similar thermoplastic elastomer behavior in DMA, with moduli 
values at least equivalent, but rather higher than those of BDO-based TPUs. In agreement with the literature, ISO was moreover found to increase Tf of MDI-based HS, but also to slightly hamper phase segregation between hard and soft domains. These results were linked to a slight increase in material hardness, shape retention and in glass transition temperature of the SS domains as well as to the appearance of very characteristic phase morphologies. Finally although isosorbide is a rather hygroscopic molecule, it induces only a very slight increase in the water uptake of these fatty acidbased TPUs when compared to BDO, thanks to the rather hydrophobic nature of the macrodiol. Although more input should be obtained from annealing and spectral analysis (such as WAXS or SAXS) studies on those samples in order to understand the nature of the thermal transitions and their relation to the phase morphology of ISO-based TPU, those elastomers might be considered as interesting and viable alternatives to entirely petro-based products.

\section{Acknowledgements}

The authors would like to thank the NMR Polymer Center of the "Institut de Chimie de Lyon" (FR3023), for assistance and access to the NMR facilities. The "Centre Technologique des Microstructures, plateforme de l'Université Claude Bernard Lyon 1", CT $\mu$ is acknowledged for granting access to their equipment.

\section{References}

Balko, J., Fernández-d’Arlas, B., Pöselt, E., Dabbous, R., Müller, A. J., Thurn-Albrecht, T., 2017. Clarifying the origin of multiple melting of segmented thermoplastic polyurethanes by fast scanning calorimetry. Macromolecules 50, 7672-7680.

Besse, V., Auvergne, R., Carlotti, S., Boutevin, G., Otazaghine, B., Caillol, S., Pascault, J.P., Boutevin, B., 2013. Synthesis of isosorbide based polyurethanes: An isocyanate free method. React. Funct. Polym. 73, 588-594.

Bueno-Ferrer, C., Hablot, E., Garrigós, M. D. C., Bocchini, S., Averous, L., Jiménez, A., 2012a. Relationship between morphology, properties and degradation parameters of novative biobased thermoplastic polyurethanes obtained from dimer fatty acids. Polym. Degrad. Stab. 97, 1964-1969.

Bueno-Ferrer, C., Hablot, E., Perrin-Sarazin, F., Garrigós, M. C., Jiménez, A., Averous, L., 2012b. Structure and morphology of new bio-based thermoplastic polyurethanes obtained from dimeric fatty acids. Macromol. Mater. Eng. 297, 777-784.

Calvo-Correas, T., Martin, M. D., Retegi, A., Gabilondo, N., Corcuera, M. A.,Eceiza, A., 2016. Synthesis and characterization of polyurethanes with high renewable carbon content and tailored properties. ACS Sustain. Chem. Eng. 4, 5684-5692.

Carré, C., Bonnet, L., Avérous, L., 2014. Original biobased nonisocyanate polyurethanes: solvent- and catalyst-free synthesis, thermal properties and rheological behavior. RSC Adv. 4, 54018-54025. 
Carré, C., Bonnet, L., Avérous, L., 2015. Solvent- and catalyst-free synthesis of fully biobased nonisocyanate polyurethanes with different macromolecular architectures. RSC Adv. 5, 100390100400 .

Carré, C., Zoccheddu, H., Delalande, S., Pichon, P., Avérous, L., 2016. Synthesis and characterization of advanced biobased thermoplastic nonisocyanate polyurethanes, with controlled aromaticaliphatic architectures. Eur. Polym. J. 84, 759-769.

Charlon, M., Heinrich, B., Matter, Y., Couzigné, E., Donnio, B., Avérous, L., 2014. Synthesis, structure and properties of fully biobased thermoplastic polyurethanes, obtained from a diisocyanate based on modified dimer fatty acids, and different renewable diols. Eur. Polym. J. 61, 197-205.

Christenson, C. P., Harthcock, M. A., Meadows, M.D., Spell, H.L., Howard, W.L.; Creswick, M.W., Guerra, R.E., Turner, R.B., 1986. Model MDI/butanediol polyurethanes: molecular structure, morphology, physical and mechanical properties. J. Polym. Sci. Part B Polym. Phys. 24, 1401-1439.

Cognet-Georjon, E., Méchin, F., Pascault, J.-P., 1995. New polyurethanes based on diphenylmethane diisocyanate and 1,4:3,6-dianhydrosorbitol, 1 . Model kinetic studies and characterization of the hard segment. Macromol. Chem. Phys. 196, 3733-3751.

Cognet-Georjon, E., Méchin, F., Pascault, J.-P., 1996. New polyurethanes based on 4,4'diphenylmethane diisocyanate and 1,4:3,6 dianhydrosorbitol, 2. Synthesis and properties of segmented polyurethane elastomers. Macromol. Chem. Phys. 197, 3593-3612.

Cuvé, L., Pascault, J.-P., Boiteux, G., 1992. Synthesis and properties of polyurethanes based on polyolefin. II. Semi-crystalline segmented polyurethanes prepared under heterogeneous or homogeneous synthesis conditions. Polymer 33, 3957-3967.

Dirlikov, S. K., Schneider, C. J., 1984. Polyurethanes based on 1;4-3:6 dianhydrohexitols. US Patent 4443563.

Fenouillot, F., Rousseau, A., Colomines, G., Saint-Loup, R., Pascault, J.-P., 2010. Polymers from renewable 1,4:3,6-dianhydrohexitols (isosorbide, isomannide and isoidide): a review. Prog. Polym. Sci. $35,578-622$.

Fernández-d'Arlas, B., Balko, J., Baumann, R. P., Pöselt, E., Dabbous, R., Eling, B., Thurn-Albrecht, T., Müller, A. J., 2016. Tailoring the morphology and melting points of segmented thermoplastic polyurethanes by self-nucleation. Macromolecules 49, 7952-7964.

Flèche, G., Huchette, M., 1986. Isosorbide. Preparation, properties and chemistry. Starch - Stärke 38, 26-30.

Ionescu, M., Petrović, Z. S., Sandhu, M. D., Javni, I., Bilić, N., Eastwood, E., 2011. New isosorbide derivatives for bio-based polyurethanes. in Polyurethanes 2011 Technical Conference, Technical Conference, Nashville (Tennesse), 144-155.

Javni, I., Bilić, O., Bilić, N., Petrović, Z. S., Eastwood, E. A., Zhang, F., Ilavský, J., 2015a. Thermoplastic polyurethanes with isosorbide chain extender. J. Appl. Polym. Sci. 132, 42830. 
Javni, I., Bilić, O., Bilić, N., Petrović, Z. S., Eastwood, E. A., Zhang, F., llavský, J., 2015b. Thermoplastic polyurethanes with controlled morphology based on methylene diphenyl diisocyanate/isosorbide/butanediol hard segments. Polym. Int. 64, 1607-1616.

Kim, H.-J., Kang, M.-S., Knowles, J. C., Gong, M.-S., 2014. Synthesis of highly elastic biocompatible polyurethanes based on bio-based isosorbide and poly(tetramethylene glycol) and their properties. J. Biomater. Appl. 29, 454-464.

Klinedinst, D. B., Yilgör, I., Yilgör, E., Zhang, M., Wilkes, G. L., 2012. The effect of varying soft and hard segment length on the structure-property relationships of segmented polyurethanes based on linear symmetric diisocyanate, 1,4-butanediol and PTMO soft segments. Polymer 53, 5358-5366.

Koberstein, J. T., Galambos, A. F., 1992. Multiple melting in segmented polyurethane block copolymers. Macromolecules 25, 5618-5624.

Lee, C.-H., Takagi, H., Okamoto, H., Kato, M., Usuki, A., 2009. Synthesis, characterization, and properties of polyurethanes containing 1,4:3,6-dianhydro-D-sorbitol. J. Polym. Sci. Part A Polym. Chem. 47, 6025-6031.

Li, C., Liu, J., Li, J.; Shen, F., Huang, Q., Xu, H., 2012. Studies of 4,4'-diphenylmethane diisocyanate (MDI)/1,4-butanediol (BDO) based TPUs by in situ and moving-window two-dimensional correlation infrared spectroscopy: understanding of multiple DSC endotherms from intermolecular interactions and motion levels. Polymer 53, 5423-5435.

Li, Y., Noordover, B. A. J., van Benthem, R. A. T. M., Koning, C. E., 2014. Reactivity and regioselectivity of renewable building blocks for the synthesis of water-dispersible polyurethane prepolymers. ACS Sustain. Chem. Eng. 2, 788-797.

Marìn, R., Muñoz-Guerra, S., 2009. Carbohydrate-based poly(ester-urethane)s: a comparative study regarding cyclic alditols extenders and polymerization procedures. J. Appl. Polym. Sci. 114, 37233736.

Marìn, R.; Alla, A.; Martinez de Ilarduya, A.; Munoz-Guerra, S. Carbohydrate-based polyurethanes: a comparative study of polymers made from isosorbide and 1,4-butanediol. J. Appl. Polym. Sci. 2012, 123, 986-994.

Oh, S.-Y., Kang, M.-S., Knowles, J. C., Gong, M.-S., 2015. Synthesis of bio-based thermoplastic polyurethane elastomers containing isosorbide and polycarbonate diol and their biocompatible properties. J. Biomater. Appl. 30, 327-337.

Oulame, M. Z., Pion, F., Allauddin, S., Raju, K. V. S. N., Ducrot, P.-H., Allais, F., 2015. Renewable alternating aliphatic-aromatic poly(ester-urethane)s prepared from ferulic acid and bio-based diols. Eur. Polym. J. 63, 186-193.

Park, H., Gong, M.-S., Knowles, J. C., 2013. Catalyst-free synthesis of high elongation degradable polyurethanes containing varying ratios of isosorbide and polycaprolactone: physical properties and biocompatibility. J. Mater. Sci. Mater. Med. 24, 281-294. 
Peebles, L. H., 1974. Sequence length distribution in segmented block copolymers. Macromolecules 7, 872-882.

Peebles, L. H., 1976. Hard block length distribution in segmented block copolymers. Macromolecules 9, 58-61.

Saiani, A., Daunch, W. A., Verbeke, H., Leenslag, J.-W., Higgins, J. S., 2001. Origin of multiple melting endotherms in a high hard block content polyurethane. I. Thermodynamic investigation. Macromolecules 34, 9059-9068.

Saiani, A., Rochas, C., Eeckhaut, G., Daunch, W. A.; Leenslag, X. J., Higgins, J. S., 2004. Origin of multiple melting endotherms in a high hard block content polyurethane. II. Structural investigation. Macromolecules 37, 1411-1421.

Saiani, A., Novak, A., Rodier, L., Eeckhaut, G., Leenslag, J.-W., Higgins, J. S., 2007. Origin of multiple melting endotherms in a high hard block content polyurethane: effect of annealing temperature. Macromolecules 40, 7252-7262.

Thiem, J., Lueders, H., 1986. Synthesis and properties of polyurethanes derived from diaminodianhydroalditols. Makromol. Chem. 187, 2775-2785.

Tsui, Y. K., Gogolewski, S., 2009. Microporous biodegradable polyurethane membranes for tissue engineering. J. Mater. Sci. Mater. Med. 20, 1729-1741.

Yilgör, I., Yilgör, E., Wilkes, G. L., 2015. Critical parameters in designing segmented polyurethanes and their effect on morphology and properties: a comprehensive review. Polymer 58, A1-A36. 